\title{
MILITARY AVIONICS FIBER OPTICS PHOTONICS PACKAGING TECHNOLOGY FORECAST
}

\author{
Mark W. Beranek, ${ }^{1}$ R. Brian Jenkins ${ }^{2}$ and Robert J. Voigt ${ }^{2}$ \\ ${ }^{I}$ Naval Air Systems Command \\ ${ }^{2}$ U.S. Naval Academy \\ Patuxent River, Maryland \\ Annapolis, Maryland
}

\section{Introduction}

Forecasting the avionics fiber optics industry photonics packaging challenges that lie ahead first requires an assumption that military avionics architectures will evolve from today's gigabit laser, optical-to-electrical-tooptical switching and optical backplane technology, to one based on gigabit tunable laser, electro-optical switch and add-drop wavelength division multiplexing (WDM) technology. It is also assumed that this future architecture will migrate away from a strictly centralized/unified concept to also support a federated/distributed network. Taking these assumptions further indicates that future avionics systems engineering will combine WDM technology with photonic circuit integration and advanced packaging to form the technical basis of the next generation military avionics onboard local area network (LAN). Ultimately Avionics Fiber Optic Built-In Test (AVOBIT) for fault detection, isolation and health monitoring will be incorporated as an integral part of a total WDM-based avionics LAN solution. Cost-effective active and passive single mode photonic component integration and packaging integration is needed to enable a reliable, maintainable and supportable WDM LAN in the harsh military avionics operational environment.

Rugged, multimode fiber-based transmitters and receivers (transceivers) with in-package AVOBIT capability continues to be needed to enable fully BIT capable single-wavelength point-to-point fiber optic links on both legacy and future aerospace platforms. ${ }^{1}$

\section{BIT-Capable WDM LAN Photonic Component Packages}

In the foreseeable future, military avionics photonics technology research will address high-speed BITcapable active and passive WDM LAN component packaging. The research will focus on both developmental and life cycle cost factors for digital and RF photonic components. Factors to consider include reliability, durability, installability, interoperability, maintainability, producibility, quality, supportability, testability and cost without sacrificing environmental and optical performance. Advanced packaging development should initially focus on polarization independent versions of the devices listed in Table 1. Active and passive device packages with detachable single mode connectors and BIT capability are also required. Ultimately, a fully BITcapable high-speed reconfigurable optical component packaging solution may evolve as an integration of bi-directional add/drop multiplexing, high-speed optical switch, tunable laser transmitter, filter, wavelength converter and lossless optical tap devices.

Table 1. Avionics WDM LAN photonic device packaging candidates.

\begin{tabular}{|c|c|}
\hline Package/Module Type & Current Priority \\
\hline $\begin{array}{c}\text { Bi-Directional Add-Drop Mux } \\
\text { (BADM) }\end{array}$ & HIGH \\
\hline IPON / LBIC (or derivative) & $\mathbf{2 , 3}$ \\
\hline Optical Switch & HIGH \\
\hline $\begin{array}{c}\text { Reconfigurable Optical } \\
\text { Add-Drop Mux (ROADM) }\end{array}$ & HIGH \\
\hline Tunable Filter & LOW \\
\hline Tunable Laser Transmitter & HIGH \\
\hline Tunable Receiver & HIGH \\
\hline Wavelength Converter & LOW \\
\hline Wavelength Selective Switch & HIGH \\
\hline
\end{tabular}


Priorities listed in Table 1 may change in the future depending on the evolution of the avionics industry's WDM networking technology development roadmap and avionics WDM LAN modeling, simulation, and laboratory test results. External influences on this prioritization could also include the SAE WDM LAN standard, new photonic integrated circuit device developments, and the maturity of the devices indicated by technology (TRL) and manufacturing readiness (MRL).

\section{BIT-Capable Single Wavelength Optoelectronic Transceiver Packages}

Future BIT-capable single wavelength optoelectronic transceiver packages are forecasted to incorporate holistic design concepts whereby BIT circuit integration, optoelectronic packaging integration, high-density detachable connector integration, and optical time domain reflectometry (or optical frequency domain reflectometry or other techniques) is applied. To be considered relevant for avionics, the BIT-capable transceiver package is expected to enable the realization of fault detection and fault isolation percentages greater than 95\%. Figure 2 summarizes the BIT-capable single wavelength optoelectronic transceiver packaging challenge that lies ahead. To address this challenge, a very highly integrated, miniaturized, connectorized and BIT-capable transceiver design and packaging technology solution is envisioned.

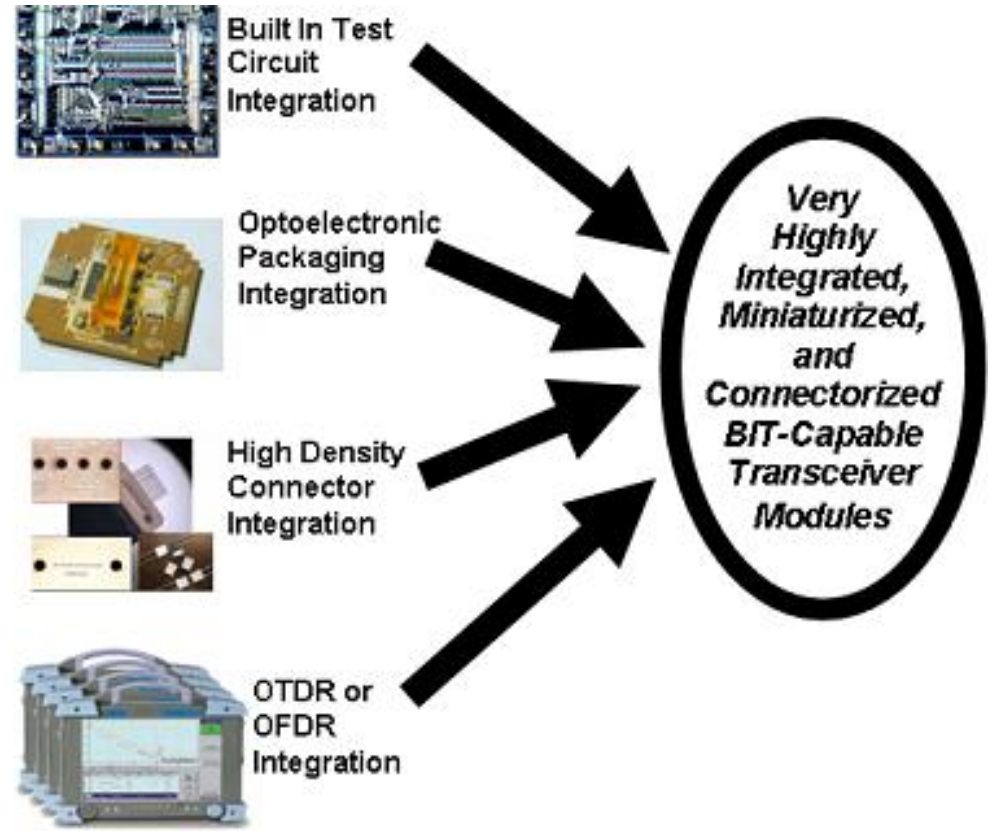

Figure 2. BIT-capable single wavelength multi-channel optoelectronic packaging challenge.

\section{Conclusion}

A new wave of photonics packaging research and development is required to enable a robust next generation BIT-capable avionics LAN technology solution based on single mode fiber and advanced WDM and RF components. Similarly, for high-speed point-to-point multimode fiber-optic links, cost-effective transmitter and receiver (transceiver) packaging with in-package optical BIT capability is needed to enable fully BITcapable fiber optic links on legacy and future military / aerospace platforms.

\section{References}

[1] M.W. Beranek, and A.R. Avak, "Improving avionics fiber optic network reliability and maintainability via built-in-test," 25th AIAA/IEEE Digital Avionics Systems Conference, Portland, OR, October, 2006.

[2] G. Abernathy, "Advanced avionics optical network," IEEE Avionics Fiber Optic and Photonics Conference, pp. 7-8, 2005.

[3] M. J. Horne, H.J. Schantz, S. O. Newcomer and G. J. Whaley, "Air Force Highly Integrated Photonics (HIP) program, Proc. of SPIE, vol. 6243, 2006. 